\title{
Digestibilidade aparente da dieta e balanço do nitrogênio em suínos de diferentes grupos genéticos com ou sem restrição alimentar
}

\author{
Apparent digestibility of the diet and nitrogen balance in different genetic groups of pigs fed ad libitum or \\ restricted
}

\author{
Claudio Sartor ${ }^{1}$ Luciano Hauschild ${ }^{1}$ Amanda d'Ávila Carvalho ${ }^{1}$ Gerson Guarez Garcia ${ }^{1}$ Marco Antônio \\ Kunrath $^{1}$ Paulo Alberto Lovatto ${ }^{1,2}$
}

\section{RESUMO}

Um experimento foi realizado com o objetivo de estudar a digestibilidade aparente da dieta e o balanço do nitrogênio em suínos de diferentes grupos genéticos com ou sem restrição alimentar. Foram utilizados 24 suínos machos castrados de três linhagens híbridas comerciais (Agroceres, Dalland e Embrapa), com peso vivo médio inicial de $47,95 \mathrm{~kg}$ e final de $52,11 \mathrm{~kg}$. Os animais foram alojados em gaiolas metabólicas mantidas em ambiente semi-climatizado. Foi utilizado um fatorial $3 \times 2$ (três linhagens híbridas comerciais com ou sem restrição alimentar), com quatro repetições cada, sendo o animal a unidade experimental. Os grupos genéticos $e$ a restrição alimentar não influenciaram $(P>0,05)$ a digestibilidade aparente da matéria seca, da proteína bruta, do extrato etéreo e a metabolizibilidade da energia. No entanto, a restrição de $20 \%$ em relação à alimentação à vontade reduziu $(P<0,05)$ em $20 \%$ a excreção urinária, $17 \%$ da excreção fecal e $19 \%$ da retenção de nitrogênio. Os grupos genéticos comerciais estudados apresentam digestibilidade, metabolização da energia e balanço do nitrogênio semelhantes. A restrição de $20 \%$ no consumo de ração não afeta a digestibilidade aparente dos nutrientes e a metabolização da energia.

Palavras-chave: alimentação, digestão, híbridos, linhagens, metabolismo.

\section{ABSTRACT}

An experiment was carried out to evaluate the digestion and metabolism of different genotypes pigs fed with or without restriction. Twenty-four barrows of three commercial genotypes were used, with $47.95 \mathrm{~kg}$ initial body weight, housed in metabolic cages maintained in semi-acclimatized atmosphere. A 3 × 2 factorial design was used (3 commercial genotypes - Agroceres, Dalland, Embrapa, with or without feed restriction), with four replications each, being the animal the experimental unit. The genotypes and feed restriction did not influence $(P>0.05)$ dry matter digestibility, crude protein, ether extract and metabolizable energy. On the nitrogen balance, restriction feed decrease $(P<0.05) 20 \%$ urinary excretion, $17 \%$ fecal losses and 19\% retention. The commercial genotypes studied have similar digestibility, metabolization energy and nitrogen balance. Restriction feed at $20 \%$ level did not affect nutrient digestibility and energy metabolization.

Key words: feed, digestion, hibrids, linkage, metabolism.

\section{INTRODUÇÃO}

A alimentação representa cerca de $70 \%$ do custo de produção de suínos. Em vista disso, novas estratégias alimentares e nutricionais têm sido utilizadas com o objetivo de reduzir esses custos. Dentre essas, destacam-se a formulação baseada no conceito de proteína ideal, dietas específicas (grupo genético, idade, sexo) e restrição alimentar (FIALHO, 2002). No entanto, essas estratégias devem considerar a adequação entre oferta nutricional da ração e exigências dos animais, o que implica conhecer os potenciais (sobretudo de ganho protéico máximo) de cada grupo genético (HALAS et al., 2004).

Normalmente as recomendações nutricionais de algumas tabelas nacionais (ROSTAGNO

${ }^{1}$ Departamento de Zootecnia (DZ), Universidade Federal de Santa Maria (UFSM), Santa Maria, RS, Brasil

${ }^{2}$ DZ, UFSM, 97105-900, Santa Maria, RS, Brasil. E-mail: lovatto@smail.ufsm.br. Autor para correspondência. 
et al., 2000) e internacionais (ARC, 1981) consideram as diferenças nutricionais determinadas pelo grupo genético de forma genérica, como por exemplo animais de alto potencial de ganho muscular. Isso sugere que as formulações das rações não sejam elaboradas pelo conceito de respostas dos animais às dietas (SAUVANT et al., 1995). Esse conceito pressupõe que seja associado um terceiro elemento aos critérios de oferta nutricional da dieta e exigências nutricionais dos animais. A capacidade que os animais de um determinado grupo genético têm de responder às dietas levando em conta as interações digestivas, metabólicas e ambientais é o elemento adicional. Um passo tímido nesse sentido foi dado pelo National Research Council (Nutrient Requirements of Swine, 1998), que apresentou um modelo flexível que leva em conta potencial de ganho muscular, temperatura ambiental e densidade animal.

Uma alternativa simples é formular as dietas para grupos genéticos específicos, ajustando a oferta nutricional às exigências do animal. Isso permite reduzir o custo da ração, melhorar a eficiência alimentar e reduzir a excreção de elementos potencialmente poluidores. Essa estratégia de formulação se justifica pelo fato dos suínos geneticamente diferentes responderem de forma diversa às manipulações alimentares e nutricionais (STEELE et al., 1974, VAREL et al., 1988, CHIBA et al, 2002). Essas respostas diferenciadas se devem às modulações digestivas e metabólicas que ocorrem em função da manipulação nutricional, refletindo em variações na deposição protéica e lipídica entre os grupos genéticos de suínos (FABIAN et al., 2003). Nesse sentido, a restrição alimentar pode contribuir com esse ajuste sem afetar negativamente o desempenho animal (BIKKER et al., 1995, BIKKER et al., 1996).

No entanto, os estudos com grupos genéticos apresentam resultados variáveis e são generalistas, não levando em conta as diferenças entre as linhagens híbridas comerciais existentes. Em vista disso, é importante que sejam realizados estudos que identifiquem as especificidades nutricionais de diferentes grupos genéticos existentes na tentativa de ajustar o aporte nutricional às respostas dos animais. Este trabalho teve, portanto, o objetivo de avaliar a digestibilidade aparente e o balanço do nitrogênio em suínos de diferentes grupos genéticos com ou sem restrição alimentar.

\section{MATERIAL E MÉTODOS}

O experimento foi realizado no Setor de Suinocultura do Departamento de Zootecnia da Universidade Federal de Santa Maria, entre janeiro e fevereiro de 2004. Foram utilizados 24 suínos machos castrados de três linhagens híbridas comerciais (Agroceres, Dalland e Embrapa). O peso médio inicial foi de 47,95 \pm 3,54 quilogramas. Os animais foram alojados em gaiolas metabólicas, mantidas em ambiente controlado a uma temperatura média de $22^{\circ} \mathrm{C}$. O delineamento experimental foi o inteiramente casualizado com repetição no tempo, sendo um fatorial 3 x 2 (três linhagens híbridas comerciais - Agroceres, Dalland e Embrapa, com ou sem restrição alimentar). Cada tratamento teve quatro repetições, sendo o animal a unidade experimental. As dietas experimentais (Tabela 1) foram formuladas utilizando o modelo e as recomendações nutricionais do NRC (1998). As dietas foram isoenergéticas, isoprotéicas, isofosfóricas e isocálcicas. O experimento teve duração de 24 dias com dois períodos de 12 dias (sete de adaptação dos animais às gaiolas e ao alimento; cinco dias de colheita de amostras). As rações foram fornecidas de acordo com o peso metabólico ( $\mathrm{PV}^{0,60}$ ) (NOBLET et al., 1993). A quantidade diária foi ajustada de acordo com a estimativa do ganho médio diário, considerando um consumo de 2,6 vezes a mantença (NOBLET et al., 1993). Os animais em restrição tiveram uma redução de $20 \%$ sobre o consumo à vontade. $\mathrm{O}$ alimento foi distribuído em três refeições diárias, às 8, 13 e 18 horas. Os animais tiveram livre acesso à água.

Foi utilizado o método de colheita de fezes, sendo o início e final da coleta determinados pelo aparecimento de fezes marcadas (foi adicionado 1,5\% de $\mathrm{Fe}_{2} \mathrm{O}_{3}$ às dietas). As fezes totais foram colhidas uma vez ao dia, acondicionadas em sacos plásticos e conservadas em congelador a $-10^{\circ} \mathrm{C}$. No final do experimento, as fezes foram homogeneizadas e amostradas $(0,5 \mathrm{~kg})$, secas em estufa de ventilação forçada $\left(60^{\circ} \mathrm{C} 72 \mathrm{~h}\right)$ e moídas para análises posteriores. A urina excretada era drenada para baldes plásticos contendo $25 \mathrm{~mL}$ de $\mathrm{HCl} 6 \mathrm{~N}$. A cada $12 \mathrm{~h}$, após 
Tabela 1 - Composições calculada e analisada da ração experimental

\begin{tabular}{lc}
\hline Ingredientes & Quantidade \\
\hline Milho & 74,34 \\
Farelo de soja & 21,59 \\
Óleo vegetal & 1,36 \\
Suplemento vitamínico e mineral &
\end{tabular}

Valores calculados

Energia metabolizável, kcal/kg

3.265

Proteína bruta, \%

16,20

Cálcio, \%

0,77

Fósforo disponível, \%

0,28

Lisina, \%

Metionina, \%

0,25

Metionina + cistina

0,53

Treonina, \%

0,52

Triptofano, \%

0,16

Arginina

0,95

Treonina, \%

Valores analisados

Matéria seca, \%

87,52

Proteína bruta, \%

16,38

Extrato etéreo, \%

3,01

${ }^{1}$ Matéria natural, composição dos alimentos segundo ROSTAGNO et al. (2000); ${ }^{2}$ Suplemento vitamínico e mineral produzido pela MIGPLUS, contendo por kg de produto: Vit. A (170.000 UI), Vit. B1 (17 mg), Vit. B2 (65 mg), Vit. B6 (34 mg), Vit. B12 (340 mg), Vit. D3 (34.000 UI), Vit. E (500 mg), Vit. K3 (35 mg), Ác. Fólico (13 mg), Ác. Nicotinico (430 mg), Ác. Pantotênico (175 mg), Ca (220 g), P (62 g), Na (62 g), promotor de crescimento (1.500 mg), Antioxidante (250 mg) homogeneização, o volume e a massa eram medidos e uma amostra de $5 \%$ do volume era retirada e conservada sob refrigeração $\left(4^{\circ} \mathrm{C}\right)$. As análises químicas das fezes e da urina foram realizadas segundo metodologia da AOAC (1995). Foram avaliados o coeficiente de digestibilidade aparente da matéria seca ( $\left.\mathrm{CD}_{\mathrm{a}} \mathrm{MS}\right)$, o coeficiente de digestibilidade aparente da proteína bruta $\left(\mathrm{CD}_{\mathrm{a}} \mathrm{PB}\right)$, o consumo de energia (CE), o coeficiente de digestibilidade aparente da energia bruta $\left(\mathrm{CD}_{\mathrm{a}} \mathrm{EB}\right)$, o coeficiente de metabolização da energia (CME) e o balanço do nitrogênio. Os valores de $\mathrm{CD}_{\mathrm{a}} \mathrm{MS}, \mathrm{CD}_{\mathrm{a}} \mathrm{PB}$, $\mathrm{CD}_{\mathrm{a}} \mathrm{EB}$ e CME foram determinados de acordo com metodologia proposta por (MATTERSON et al., 1965). Os dados obtidos foram submetidos à análise de variância incluindo no modelo os efeitos do período (P), grupos genéticos (GG), programa alimentar (PA) e interação $G^{*} P A$. As comparações de médias foram feitas pelo teste de Tukey a 5\% de significância. As análises estatísticas foram realizadas através do programa Minitab (MCKENZIE \& GOLDMAN, 1999).

\section{RESULTADOSE DISCUSSÃO}

Na tabela 2, são apresentados os coeficientes de digestibilidade aparente da MS e da PB de dietas para diferentes grupos genéticos de suínos alimentados com dois programas alimentares. Não houve efeito $(\mathrm{P}>0,05)$ do grupo genético, do programa alimentar nem da interação desses dois fatores sobre o $\mathrm{CD}_{\mathrm{a}} \mathrm{MS}$ e $\mathrm{CD}_{\mathrm{a}} \mathrm{PB}$. Esses resultados podem ser explicados pelo potencial máximo de deposição protéica (PDmax) elevado e homogêneo entre os grupos genéticos estudados. Os suínos selecionados para deposição de carne magra possuem maior massa visceral comparada a grupos genéticos inferiores (POND et al., 1988). Esta diferença tem influência na atividade do trato gastrintestinal, com melhora na digestibilidade da MS, da PB e absorção dos nutrientes (FABIAN et al., 2003). Durante a restrição alimentar o aproveitamento dos alimentos é diferenciado, em função da menor massa dos órgãos do sistema digestório (POND \& MERSMANN, 1990). A alteração de massa de órgãos do sistema digestório de suínos submetidos à restrição alimentar quali ou quantitativa depende da 
Tabela 2 - Coeficientes de digestibilidade aparente da matéria seca $\left(\mathrm{CD}_{\mathrm{a}} \mathrm{MS}\right)$ e da proteína bruta $\left(\mathrm{CD}_{\mathrm{a}} \mathrm{PB}\right)$ de dietas para suínos de diferentes grupos genéticos com ou sem restrição

\begin{tabular}{|c|c|c|}
\hline \multirow{2}{*}{ Grupos genéticos } & \multicolumn{2}{|c|}{ Parâmetros avaliados } \\
\hline & $\mathrm{CD}_{\mathrm{a}} \mathrm{MS}, \%$ & $\mathrm{CD}_{\mathrm{a}} \mathrm{PB}, \%$ \\
\hline Agroceres & 86,92 & 85,76 \\
\hline Dalland & 85,56 & 84,93 \\
\hline Embrapa & 87,37 & 87,37 \\
\hline À vontade & 86,93 & 86,07 \\
\hline Restrito (-20\%) & 86,33 & 85,97 \\
\hline dpr & 2,19 & 2,96 \\
\hline Efeito & NS & NS \\
\hline
\end{tabular}

dpr, desvio padrão residual; NS, não significativo $(\mathrm{P}>0,05)$

intensidade e do tempo de restrição (SENCKENBERG et al., 1984, LOVATTO et al., 2000). O pouco tempo e a baixa intensidade da restrição realizadas no presente experimento podem não ter sido suficientes para alterar a digestibilidade da dieta, devido à provável não alteração das massas dos órgãos do sistema digestório. A ingestão, digestibilidade e metabolizibilidade da energia são apresentadas na tabela 3. A ingestão de energia não diferiu $(\mathrm{P}>0,05)$ entre os diferentes grupo genéticos, mas obviamente foi $17 \%$ menor $(\mathrm{P}<0,05)$ nos animais com restrição alimentar. A digestibilidade e a metabolizibilidade da energia não foi influenciada $(\mathrm{P}<0,05)$ pelos grupos genéticos e pelo programa alimentar. Estes resultados mostram que os grupos genéticos estudados não apresentam diferenças na digestibilidade e metabolizibilidade da energia e que a restrição de $20 \%$ não interfere na utilização digestiva e metabólica da energia. Como foi descrito anteriormente, os suínos de grupos genéticos selecionados para deposição de carne magra possuem atividade digestiva e metabólica dos órgãos mais intensa comparada a grupos genéticos inferiores (FERREL, 1988). Embora esta característica fisiológica possa melhorar a digestibilidade e metabolizibilidade da energia, a perda excessiva de calor associada à mantença leva a repostas diferenciadas no balanço energético destes animais (NOBLET et al., 1999). A metabolização da energia para dois tipos de linhagens híbridas comerciais pode ser diferenciada, com resultados favoráveis ao grupo genético com PDmax mais elevado (PIMENTA et al., 2000). Com uma redução energética de $20 \%$ em dietas para suínos de diferentes grupo genéticos ocorreu uma metabolização da energia favorável à menor deposição lipídica nos grupo genéticos inferiores (NOSSAMAN et al., 1991). Estes trabalhos evidenciam a interação entre grupo genético e plano nutricional, com diferenças na metabolização da energia.

O balanço do nitrogênio ( $\mathrm{N}$ ) é apresentado na tabela 4. Não houve diferença $(\mathrm{P}>0,05)$ entre os grupos genéticos nem interação grupo genético $\mathrm{e}$ programa alimentar, nos parâmetros avaliados. No programa alimentar a retenção de $\mathrm{N}$ em função da absorção não diferiu ( $\mathrm{P}>0,05)$; mas houve diferença $(\mathrm{P}<0,05)$ para consumo, excreção, absorção e retenção. A restrição reduziu $(P<0,05)$ 20\% da excreção urinária, $17 \%$ da excreção fecal, 17\% a absorção e $19 \%$ a retenção de N. Esses resultados confirmam dados experimentais que demonstram alta correlação entre ingestão e excreção fecal de N (HENNIG et al., 1982). As estimativas de $\mathrm{N}$ urinário e retido em função do absorvido por apresentarem correlação com a utilização metabólica dos aminoácidos são utilizadas para explicar a eficiência da síntese protéica (HENNIG et al., 1982). Os grupos genéticos de suínos selecionados para deposição de carne magra são mais eficientes na retenção de $\mathrm{N}$ e na utilização de aminoácidos (CHIBA et al., 2002). Em dietas para suínos de duas linhagens híbridas comerciais selecionadas para PDmax elevados, a retenção de $\mathrm{N}$ diferiu em $8 \%$ na fase de crescimento e em $4 \%$ na terminação, contudo essa diferença não se traduziu em ganho muscular (GOMES et al., 2000). A diferença na retenção de $\mathrm{N}$ entre os grupos genéticos foi demonstrada em vários trabalhos, sendo associada à composição genética dos suínos (SUSENBETH et al., 1999, GOMES et al., 2000). 
Tabela 3 - Consumo de energia e coeficientes de digestibilidade aparente da energia bruta $\left(\mathrm{CD}_{a} \mathrm{~EB}\right)$ e da metabolização (CME) da energia de dietas para suínos de diferentes grupos genéticos com ou sem restrição

Parâmetros avaliados

Grupos genéticos

Energia ingerida, kcal/dia

$\mathrm{CD}_{a} \mathrm{~EB}, \%$

CME, \%

\begin{tabular}{lccc} 
Agroceres & 5.178 & 87,58 & 85,21 \\
Dalland & 5.353 & 86,40 & 83,45 \\
Embrapa & 5.391 & 88,28 & 85,42 \\
& & & 84,87 \\
À vontade & 5.789 & 87,68 & 84,50 \\
Restrito (-20\%) & 4.826 & 87,11 & 2,57 \\
dpr & & & NS \\
Efeito & 371 & 2,15 & NS \\
\hline
\end{tabular}

dpr, desvio padrão residual; NS, não significativo; PA, plano alimentar, $(\mathrm{P}<0,05)$

A eficiência nutricional de grupos genéticos distintos pode estar relacionada ao programa nutricional ou alimentar. A restrição alimentar ou níveis sub-ótimos de nutrientes induzem a modulações no trato gastrintestinal e respectiva melhora no aproveitamento dos alimentos (CHIBA et al., 1999). Em relação ao metabolismo, a restrição induz ao aumento da eficiência da síntese protéica pela redução da oxidação dos aminoácidos (REEDS et al., 1981).

Os animais submetidos à restrição apresentam melhor eficiência de utilização dos aminoácidos (FABIAN et al., 2002). Embora o N retido tenha sido inferior na alimentação restrita, os dados deste experimento confirmam esses resultados, pois os grupos genéticos apresentaram respostas semelhantes na estimativa de $\mathrm{N}$ retido em função do absorvido diante dos programas alimentares. Os resultados observados neste trabalho sugerem que sejam realizados estudos com restrições variadas, na tentativa de identificar pontos de ajuste mais precisos entre ingestão e retenção de nutrientes.

\section{CONCLUSÕES}

Os grupos genéticos comerciais estudados apresentam digestibilidade aparente, metabolizibilidade da energia e balanço do nitrogênio semelhantes.

A redução de $20 \%$ no consumo de alimento não afeta a digestibilidade dos nutrientes e metabolização da energia. A restrição alimentar reduz as excreções fecal, urinaria e a retenção de nitrogênio.

\section{AGRADECIMENTOS}

Os autores agradecem ao Programa de Pós graduação em Zootecnia (PPGZ/UFSM), ao Conselho Nacional para o Desenvolvimento Científico e Tecnológico (CNPq), pela bolsa concedida ao mestrando Luciano Hauschild e à Fundação de Amparo à Pesquisa do Rio Grande do Sul

Ciência Rural, v.36, n.2, mar-abr, 2006. 
Tabela 4 - Nitrogênio ingerido (Ni), excretado nas fezes (Nf) e na urina (Nu), absorvido (Na), retido (Nr) e retido em função do absorvido (Nr/a) de suínos de diferentes grupos genéticos com ou sem restrição

\begin{tabular}{|c|c|c|c|c|c|c|}
\hline \multirow{2}{*}{ Grupos genéticos } & \multicolumn{6}{|c|}{ Parâmetros } \\
\hline & Ni, g/dia & Nf*, g/ dia & $\mathrm{Nu}^{*}, \mathrm{~g} / \mathrm{dia}$ & $\mathrm{N} \mathrm{a}^{*}, \mathrm{~g} / \mathrm{dia}$ & $\mathrm{Nr}^{*}, \mathrm{~g} / \mathrm{dia}$ & $\mathrm{Nr} / \mathrm{a}, \%$ \\
\hline Agroceres & 37,29 & 6,30 & 13,76 & 30,99 & 17,23 & 55,78 \\
\hline Dalland & 36,07 & 5,82 & 10,72 & 30,25 & 19,54 & 64,88 \\
\hline Embrapa & 37,56 & 5,38 & 13,39 & 32,17 & 18,78 & 58,08 \\
\hline À vontade & 40,89 & 6,39 & 14,05 & 33,99 & 20,48 & 60,53 \\
\hline Restrito (-20\%) & 33,05 & 5,30 & 11,20 & 28,28 & 16,55 & 58,62 \\
\hline dpr & 1,56 & 1,19 & 3,54 & 2,83 & 4,21 & 11,16 \\
\hline Efeito & $\mathrm{PA}$ & PA & PA & PA & $\mathrm{PA}$ & NS \\
\hline
\end{tabular}

dpr, desvio padrão residual; NS, não significativo, * NI utilizado como covariável; PA, plano alimentar; $(\mathrm{P}<0,05)$

(FAPERGS), pela bolsa de iniciação científica concedida a Marco Antônio Kunrath

\section{REFERÊNCIAS}

AOAC. Official Methods of Analysis. 17.ed. Arlington, VA, 1995. 1141p.

ARC. The nutrients requirements of pigs: technical review. London, England: Commonwealth Agricultural Burreaux, 1981. 307p.

BIKKER, P. et al. Protein and lipid accretion in body components of growing gilts (20 to 45 kilograms) as affected by energy intake. Journal of Animal Science. v.73, p.23552363, 1995.

BIKKER, P. et al. Performance and body composition of finishing gilts (45 to 85 kilograms) as affected by energy intake and nutrition in earlier life: II. Protein and lipid accretion in body components. Journal of Animal Science. v.74, p.817826, 1996.

CHIBA, L.I. et al. Growth performance and carcass traits of pigs subjected to marginal dietary restrictions during the grower phase. Journal of Animal Science. v.77, p.1769-1776, 1999.
CHIBA, L.I. et al. Effect of dietary restrictions on growth performance and carcass quality of pigs selected for lean growth efficiency. Livestock Production Science v.74, p.93-102, 2002.

FABIAN, J. et al. Degree of amino acid restrictions during the grower phase and compensatory growth in pigs selected for lean growth efficiency. Journal of Animal Science. v.80, p.2610-2618, 2002.

FABIAN, J. et al. Growth performance, dry matter and nitrogen digestibilities, serum profile, and carcass and meat quality of pigs with distinct genotypes. Journal of Animal Science, v.81, p.1142-1149, 2003.

FERREL, C. L. Contribution of visceral organs to animal energy expenditures. Journal of Animal Science v.66, Suppl. 3, p.23-34, 1988.

FIALHO, E.T. Redução da poluição por dejetos de suínos: aspectos nutricionais. In: SIMPÓSIO DE MANEJO E NUTRIÇÃO DE AVES E SUÍNOS E TECNOLOGIA DA PRODUÇÃO DE RAÇÕES, 2002, Campinas, SP. Anais... Campinas, SP: CBNA, 2002. p.294.

GOMES, F.E. et al. Planos de nutrição baseados em níveis de lisina para suínos de diferentes grupo genéticos abatidos aos 80 
e $100 \mathrm{~kg}$ de peso vivo. Ciência Agrotecnica, v.24, p.479489, 2000.

HALAS, V. et al. Modelling of nutrient partitioning in growing pigs to predict their anatomical body composition. 2. Model evaluation. Brithish Journal Nutrition, v.92, p.725-734 2004.

HENNIG, U. et al. Effect of graded protein supply at highenergy level on the fattening performance and the retention and utilization of feed energy, protein and amino acids by female fattening swine. 3 . $\mathrm{N}$ retention and $\mathrm{N}$ and lysine metabolism determined by $\mathrm{N}$ balance and $\mathrm{N}$ analysis of the carcasses. Archieve Tierernahr, v.32, p.637-649, 1982.

LOVATTO, P.A. et al. Etude de la modélisation du phénomène de croissance compensatrice chez le porc. Journées Rechearch Porcine en France, v.32, p.241-246, 2000.

MATTERSON, L.D. et al. The metabolizable energy of feed ingredients for chickens. Connecticut: University of Connecticut, Agricultural experiment station, 1965. 7p.

MCCONNELL, J.C. et al. Nutrient digestibility and nitrogen metabolism studies at different stages of growth with fat and lean type swine fed two levels of protein. Journal of Animal Science, v.32, p.654-657, 1971.

MCKENZIE, J.; GOLDMAN, R.N. The student edition of Minitab for Windows manual: release 12 . Belmont: Addison-Wesley Longman, Incorporated, 1999. 592p. (Softcover ed.).

NOBLET, J. et al. Metabolic utilization of energy and maintenance requirements in growing pigs: effects of sex and genotype. Journal of Animal Science, v.77, p.1208-1216, 1999.

NOBLET, J. et al. Metabolic utilization of dietary energy and nutrients for maintenance energy requirements in sows: basis for a net energy system. Brithish Journal Nutrition, v.70, p.407-419, 1993.

NOSSAMAN, D.A. et al. Interaction of somatotropin and genotype on the requirement for energy in two lines of finishing pigs. Journal Nutrition, v.121, p.223-230, 1991.

NRC. Nutrient requirements of swine. 10.ed. Washington: National Academy, 1998. 189p.
PIMENTA, M.E.S.G. et al. Balanço protéico e energético de rações com diferentes níveis de proteína em suínos de dois grupo genéticos diferentes. Ciência Agrotecnica, v.24, p.287294, 2000.

POND, W.G. et al. Effect of dietary fiber on young adult genetically lean, obese and contemporary pigs: body weight, carcass measurements, organ weights and digesta content. Journal of Animal Science, v.66, p.699-706, 1988.

POND, W.G.; MERSMANN, H.J. Differential compensatory growth in swine following control feed intake by a high-alfafa diet fed ad libitum or by limited feed. Journal of Animal Science, v.68, p.352, 1990.

POND, W.G.; YEN, J.T. Effect of protein deficiency on growth and plasma zinc concentration in genetically lean and obese swine. Journal of Animal Science, v.59, p.710-716, 1984.

REEDS, P.J. et al. Effect of changes in the intakes of protein ands non - protein energy on whole - body protein turnover in growing pigs. British Journal Nutrition, v.45, p.539-546, 1981.

ROSTAGNO, H.S. et al. Tabelas brasileiras para aves e suínos. Composição de alimentos e exigências nutricionais. Viçosa: Universidade Federal de Viçosa, 2000. 141p.

SAUVANT, D. et al. Systèmes d'unités d'alimentation et lois de réponse du porc aux régimes alimentaires. Journées Recherch Porcine France, v.27, p.237-244, 1995.

SENCKENBERG, E. et al. Effect of protein restriction and refeeding on the nitrogen balance in piglets. Archieve Tierernahr, v.34, p.457-466, 1984.

STEELE, N.C. et al. Lipogenesis and cellularity of adipose tissue from genetically lean and obese swine. Journal of Animal Science, v.39, p.712-719, 1974.

SUSENBETH, A. et al. The effect of energy intake, genotype, and body weight on protein retention in pigs when dietary lysine is the first-limiting factor. Journal of Animal Science, v.77, p.2985-2989, 1999

VAREL, V.H. et al. Effects of dietary fiber of young adult genetically lean, obese and contemporary pigs: rate of passage, digestibility and microbiological data. Journal of Animal Science, v.66, p.707-712, 1988. 